\title{
BMJ Open HbA1c variability in adults with type 1 diabetes on continuous subcutaneous insulin infusion (CSII) therapy compared to multiple daily injection (MDI) treatment
}

\author{
Emma S Scott (D) ,,2 Rachel T McGrath, ${ }^{2,3}$ Andrzej S Januszewski, ${ }^{1,4}$ \\ Daniel Calandro, ${ }^{1}$ Anandwardhan A Hardikar, ${ }^{1}$ David N O'Neal (D) , 5,6 \\ Gregory Fulcher, ${ }^{2,3}$ Alicia J Jenkins ${ }^{1,5}$
}

To cite: Scott ES, McGrath RT, Januszewski AS, et al. HbA1c variability in adults with type 1 diabetes on continuous subcutaneous insulin infusion (CSII) therapy compared to multiple daily injection (MDI) treatment. BMJ Open 2019;9:e033059. doi:10.1136/ bmjopen-2019-033059

- Prepublication history and additional material for this paper are available online. To view these files, please visit the journal online (http://dx.doi. org/10.1136/bmjopen-2019033059).

Received 23 July 2019 Revised 23 November 2019 Accepted 02 December 2019

Check for updates

(C) Author(s) (or their employer(s)) 2019. Re-use permitted under CC BY-NC. No commercial re-use. See rights and permissions. Published by BMJ.

For numbered affiliations see end of article.

Correspondence to

Professor Alicia J Jenkins;

alicia.jenkins@ctc.usyd.edu.au

\section{ABSTRACT}

Objective To determine if continuous subcutaneous insulin infusion (CSII) therapy is associated with lower glycatedhaemoglobin ( $\mathrm{HbA1c}$ ) variability (long-term glycaemic variability; GV) relative to multiple daily injection (MDI) treatment in adults with type 1 diabetes mellitus (T1DM).

Design Retrospective audit.

Setting and participants Clinic records from 506 adults with T1DM from two tertiary Australian hospitals.

Outcome measures Long-term GV was assessed by $\mathrm{HbA1c}$ SD and coefficient of variation (CV) in adults on established MDI or CSII therapy, and in a subset changing from MDI to CSII.

Results Adults ( $\mathrm{n}=506$, (164 CSII), 50\% women, mean \pm SD age $38.0 \pm 15.3$ years, $17.0 \pm 13.7$ years diabetes, mean $\mathrm{HbA} 1 \mathrm{c} 7.8 \% \pm 1.2 \%(62 \pm 13 \mathrm{mmol} / \mathrm{mol})$ on CSIl, $8.0 \% \pm 1.5 \%$ ( $64 \pm 16 \mathrm{mmol} / \mathrm{mol})$ on $\mathrm{MDI})$ were followed for $4.1 \pm 3.6$ years. CSIl use was associated with lower GV (HbA1c SD: CSIl vs MDI 0.5\% $\pm 0.41 \%(6 \pm 6 \mathrm{mmol} /$ mol) vs $0.7 \% \pm 0.7 \%(9 \pm 8 \mathrm{mmol} / \mathrm{mol}))$ and $\mathrm{CV}$ : CSIl vs MDI $6.7 \% \pm 4.6 \%(10 \pm 10 \mathrm{mmol} / \mathrm{mol})$ vs $9.3 \% \pm 7.3 \%$ $(14 \pm 13 \mathrm{mmol} / \mathrm{mol})$, both $p<0.001$. Fifty-six adults $(73 \%$ female, age $36 \pm 13$ years, $16 \pm 13$ years diabetes, $\mathrm{HbA} 1 \mathrm{c}$ $7.8 \% \pm 0.8 \%(62 \pm 9 \mathrm{mmol} / \mathrm{mol}))$ transitioned from $\mathrm{MDI}$ to CSII. Mean HbA1c fell by $0.4 \%$. GV from 1 year post-CSII commencement decreased significantly, HbA1c SD preCSIl versus post-CSII $0.7 \% \pm 0.5 \%(8 \pm 5 \mathrm{mmol} / \mathrm{mol})$ vs $0.4 \% \pm 0.4 \%$ ( $5 \pm 4 \mathrm{mmol} / \mathrm{mol}) ; \mathrm{p}<0.001$, and $\mathrm{HbA} 1 \mathrm{c} \mathrm{CV}$ $9.2 \% \pm 5.5 \%(13 \pm 8 \mathrm{mmol} / \mathrm{mol})$ vs $6.1 \% \pm 3.9 \%(9 \pm 5 \mathrm{mmol} /$ mol); $p<0.001$.

Conclusions In clinical practice with T1DM adults relative to MDI, CSII therapy is associated with lower HbA1c GV.

\section{INTRODUCTION}

Type 1 diabetes mellitus (T1DM) is characterised by day-to-day glucose fluctuations, much more so than in type 2 diabetes mellitus (T2DM). The Diabetes Control and Complications Trial established that near normal glycaemic control, reflected by glycated

\section{Strengths and limitations of this study}

- A relatively large real-world observational study across a wide age and socioeconomic status from two tertiary hospitals allows for generalisability of results.

- Glycated haemoglobin glycaemic variability (GV), a simple low-cost mathematical measure, assessed using two formulae, with similar results, and in venous blood in accredited laboratories.

- Analysis in those on established multiple daily injection (MDI) or continuous subcutaneous insulin infusion therapy and in a subset who changed modalities, and a control group of MDI users who remained on $\mathrm{MDI}$.

- Not a randomised study therefore not able to completely adjust for possible behavioural differences.

- Complements and extends a prior publication by the group in which short-term GV based on interstitial fluid continuous glucose monitoring (CGM) measures did not differ by insulin delivery modality.

haemoglobin (HbA1c) levels, substantially reduces the risk of long-term vascular and neurological complications. ${ }^{1}$ Short-term glycaemic variability (GV) can be assessed by analysing multiple daily capillary blood glucose levels, or by continuous (interstitial fluid) glucose monitoring (CGM), and at cellular level has been demonstrated ${ }^{2}$ to increase oxidative stress, inflammation and epigenetic changes. ${ }^{4}$ Longer-term GV can be assessed by analysing variation in HbAlc levels over time, usually reported as HbA1c SD and/ or coefficient of variation (CV), and has been implicated as an independent risk factor for the development of chronic complications in people with both T1DM and T2DM. ${ }^{4-7}$ Shortterm and long-term GV do not always correlate. 
In people with T1DM, insulin can be delivered by either multiple daily injections (MDI) or by continuous subcutaneous insulin infusion (CSII). There is emerging epidemiological evidence that CSII use (independent of HbAlc levels) is associated with a reduction in chronic complications in both adult and paediatric age groups and with reduced cardiovascular mortality in adults with T1DM. ${ }^{58}$ Although CSII use is generally associated with lower $\mathrm{HbAlc}$ levels compared with $\mathrm{MDI},{ }^{9}$ there are no consistent reported associations in the literature between short-term and long-term GV and insulin delivery mode. CSII without frequent real-time continuous glucose monitoring (RT-CGM) is usually associated with similar shortterm GV as MDI, ${ }^{10-12}$ including in our previous study in T1DM adults in the same setting as herein. With regard to long-term GV, there is only one published study, and that is in a paediatric setting, which demonstrated longterm GV benefit of CSII compared with MDI over a 3 year period. ${ }^{13}$

The primary aim of the present study was to examine HbA1c GV in adults with T1DM treated by CSII and MDI therapies predominantly without RT-CGM use in the realworld setting, not in a clinical trial. Hence, we compared HbA1c SD and CV over years in adults with T1DM treated by CSII, to those of adults treated by MDI, and also in those changing from MDI to CSII therapy. Results were analysed with and without adjustment for mean HbAlc levels. As glycaemic benefit of technology may differ by user age group, ${ }^{14}$ we also compared results in emerging adults (aged 18 to 26 years) and more mature adults ( $\geq 26$ years).

\section{MATERIALS AND METHODS \\ Subjects}

We undertook a retrospective audit of clinical records of adults with T1DM attending outpatient diabetes clinics at two independent tertiary referral hospitals (Royal North Shore Hospital (RNSH), Sydney, and St Vincent's Hospital (SVH), Melbourne, Australia). Data from 1995 to 2018 were collected. Participants were excluded if they were less than 18 years old, pregnant or breastfeeding, had less than two HbAlc results on record or had less than 1 year of CSII therapy. The insulin pumps were not used with continuous RT-CGM. Flash glucose monitoring became available in Australia in late 2016 and was not subsidised, and RT-CGM only became subsidised for those under 21 years of age in 2017, therefore these modalities were rarely used in our public hospital settings during the study period.

\section{Patient and public involvement}

No patients were involved. As this was a retrospective audit, it was not appropriate or possible to directly involve patients or the public in this work.

\section{Data collection}

All HbA1c results were obtained from laboratories accredited with the National Association of Testing Authorities
(NATA) and the Royal College of Pathologists of Australasia. All NATA accredited laboratories are required to participate in a standardisation programme and to standardise HbAlc measurements to the International Federation of Clinical Chemistry and Laboratory Medicine guidelines. Patients usually had their laboratory tests performed by the same pathology provider. Demographic and clinical parameters (including insulin treatment modality, chronic complication status, incidence of severe hypoglycaemia (defined as any episode of hypoglycaemia requiring assistance from another person for recovery)) were obtained from the medical records. Socioeconomic status was estimated via the subject's home address postcode (zip code) via the Australian Bureau of Statistics Socio-Economic Indexes for Areas, 2011. ${ }^{15}$

\section{Glycaemic variability}

HbA1c GV was assessed through the mean withinindividual SD and CV ((SD HbA1c/mean HbA1c) x 100) of available HbA1c levels. If individuals had changed treatment modality from MDI to CSII, the initial 12 months of $\mathrm{HbAlc}$ assessments post-CSII initiation were excluded, (as HbAlc usually decreases significantly during this time). ${ }^{1617}$

\section{Statistical analyses}

Data were stored in Excel (2010) and IBM SPSS Statistics (V.22) and GraphPad Prism (V.6.0) were used for data analyses, including descriptive statistics, paired and independent T-tests, $\mathrm{X}^{2}$ tests and Pearson correlation coefficients. Statistical significance was taken at $p<0.05$. Results were analysed as a whole and with subgroup analyses by age (18 to $<26$ years and $\geq 26$ years) and by gender. A further subgroup analysis assessed the impact of insulin modality on GV across tertiles of mean HbAlc using a general linear model. Participants on established insulin therapies (MDI or CSII) were analysed, as were a group of individuals analysed pre-insulin and post-insulin modality change (MDI to CSII). The participants who changed from MDI to CSII were matched (by age, baseline HbAlc and years of follow-up) to a subgroup of adults who remained on MDI. GV was compared pre-modality and after 1 year post-modality change in the MDI to CSII group, and pre and post a matched duration of follow-up in the group who remained on MDI. Where applicable, results were analysed with adjustment by least squares method for hospital location, gender, vascular complications, severe hypoglycaemia, age, diabetes duration, mean HbAlc levels, number of included HbAlc measurements, time between HbAlc measurements, years of follow-up, average decile of socioeconomic advantage and disadvantage and decile of education and occupation.

\section{RESULTS}

\section{Subject demographics}

Baseline clinical characteristics of 506 adults with T1DM studied over time while on a single insulin delivery 
Table 1 Clinical characteristics of adults with type 1 diabetes mellitus

\begin{tabular}{llll}
\hline & CSII & MDI & P value \\
\hline $\mathrm{N}$ & 164 & 342 & \\
\hline Age (years) & $34 \pm 13.4$ & $39 \pm 15.8$ & $<0.001$ \\
\hline Women (n (\%)) & $106(65)$ & $148(43)$ & $<0.001$ \\
\hline Years of diabetes & $17 \pm 12.5$ & $18 \pm 14.3$ & 0.55 \\
\hline Years CSIl therapy & $6.0 \pm 3.6$ & $\mathrm{~N} / \mathrm{A}$ & - \\
\hline $\begin{array}{l}\text { Vascular complications } \\
\text { (n (\%)) }\end{array}$ & $49(30)$ & $143(42)$ & $\mathbf{0 . 0 0 8}$ \\
$\begin{array}{l}\text { Severe hypoglycaemia } \\
\text { (n (\%))† }\end{array}$ & $14(14)$ & $70(21)$ & $\mathbf{0 . 0 4 5}$ \\
$\begin{array}{l}\text { Socioeconomic status } \\
\text { (decile): }\end{array}$ & $8 \pm 2.3$ & $9 \pm 1.9$ & $\mathbf{0 . 0 0 5}$ \\
$\begin{array}{l}\text { advantage/disadvantage } \\
\text { education \& occupation }\end{array}$ & $8 \pm 2.4$ & $9 \pm 1.9$ & $<0.001$ \\
\hline $\begin{array}{l}\text { Years follow-up } \\
\text { HbA1c measures (n) }\end{array}$ & $8.1 \pm 2.7$ & $4.1 \pm 4.0$ & 0.90 \\
\hline $\begin{array}{l}\text { Time between HbA1c } \\
\text { (days) }\end{array}$ & $213 \pm 173$ & $8 \pm 8$ & 0.96 \\
\hline $\begin{array}{l}\text { Mean HbA1c \% (mmol/ } \\
\text { mol) }\end{array}$ & $7.8 \pm 1.2$ & $8.0 \pm 1.5$ & 0.13 \\
\hline
\end{tabular}

Data are mean $\pm \mathrm{SD}$, or $\mathrm{n}$ (percentage).

*Microvascular and/or macrovascular complications.

†Any episode of severe hypoglycaemia recorded in the medical record.

CSII, continuous subcutaneous insulin infusion; HbA1c, glycated haemoglobin; MDI, multiple daily injection.

modality are shown in table 1 , with participants from both hospitals merged. The group is also described based on insulin delivery mode. SVH participants $(n=112)$ were more likely to be treated by CSII compared with the RNSH participants $(66(59 \%)$ vs $98(25 \%)$; p <0.001) as SVH was an earlier adopter of CSII into their clinical practice. SVH subjects were more likely to be female, had fewer vascular complications, lower socioeconomic status, longer years of $\mathrm{HbAlc}$ follow-up and more available HbAlc measurements compared with the RNSH participants (online supplementary table 1). The (merged sites, table 1) CSII users were younger, more likely to be female (in keeping with a noted national trend, ${ }^{18}$ and less likely to have vascular complications or a previous documented episode of severe hypoglycaemia and had a significantly lower socioeconomic status relative to the MDI group. There were no significant differences in the years of follow-up between the CSII and MDI groups, nor the number of HbAlc measurements included in the study. CSII users had a slightly shorter mean \pm SD time between HbAlc measurements compared with MDI users $(213 \pm 173$ vs $249 \pm 203$ days, respectively; $\mathrm{p}=0.047)$. There were no significant differences in mean HbAlc levels nor the number of measures evaluated over the study period between the CSII and MDI groups (HbAlc mean (SD) $7.8 \% \pm 1.2 \%(62 \pm 13) \mathrm{mmol} / \mathrm{mol}(\mathrm{n}=8 \mathrm{HbAlc}$ measures$)$
CSII, and HbAlc mean (SD) $8.0 \% \pm 1.5 \%(64 \pm 16) \mathrm{mmol} /$ mol ( $\mathrm{n}=8$ HbA1c measures) MDI; $\mathrm{p}=0.13$ ).

\section{Lower HbA1c GV in CSII users}

CSII-users had significantly lower long-term variability in HbAlc as reflected by both HbA1c SD and CV measures (figure 1). The difference remains statistically significant after adjustment (least squares) for gender, hospital location, chronic complication status, severe hypoglycaemia, baseline HbA1c levels, years of follow-up, number of HbAlc measures, time between HbAlc tests, diabetes duration, socioeconomic status and age (both $\mathrm{p}=0.003$ ). In order to account for possible differences in glycaemic control by hospital location, insulin modality treatments were compared separately at the two sites and similar significantly lower GV was observed in CSII (vs MDI) users (online supplementary figure 1). GV was also analysed by gender, and similarly lower HbA1c SD and CV was observed in CSII compared with MDI participants in both men and women. HbA1c SD in women $(0.6 \% \pm 0.5 \%$ $(7 \pm 6) \mathrm{mmol} / \mathrm{mol} \mathrm{CSII}, 0.8 \% \pm 0.7 \% \quad(9 \pm 8) \mathrm{mmol} / \mathrm{mol}$ MDI, $\mathrm{p}=0.005)$ and in men $(0.4 \% \pm 0.3 \%(5 \pm 3) \mathrm{mmol} /$ mol CSII, $0.8 \% \pm 0.7 \%(9 \pm 8) \mathrm{mmol} / \mathrm{mol} \mathrm{MDI}, \mathrm{p}=0.002)$. HbAlc CV in women $(7 \% \pm 5 \%(11 \pm 12) \mathrm{mmol} / \mathrm{mol} \mathrm{CSII}$, $9 \% \pm 8 \%(14 \pm 12) \mathrm{mmol} / \mathrm{mol}$ MDI, $\mathrm{p}=0.02)$ and in men $(6 \% \pm 3 \%(8 \pm 4) \mathrm{mmol} / \mathrm{mol} \mathrm{CSII,} 9 \% \pm 7 \%(15 \pm 13) \mathrm{mmol} /$ mol MDI, $\mathrm{p}=0.002)$.

\section{Similar pattern of HbA1c variability in adults with T1DM by age group and insulin treatment modality}

Analysis by predetermined age-subgroups (18 to $<26$ years and $\geq 26$ years) demonstrated that mean $\mathrm{HbA1c}$ was lower in the older CSII versus older MDI users: $(7.6 \% \pm 1.1 \%(59 \pm 12) \mathrm{mmol} / \mathrm{mol}$ CSII and $7.9 \% \pm 1.4 \%$ $(62 \pm 16) \mathrm{mmol} / \mathrm{mol} \mathrm{MDI} ; \mathrm{p}=0.034)$, although there was no statistically significant difference in the 18 to $<26$ year old group: (CSII vs MDI; $8.3 \% \pm 1.3 \%(66 \pm 14) \mathrm{mmol} /$ $\mathrm{mol}$ vs $8.5 \% \pm 1.6 \%(68 \pm 18) \mathrm{mmol} / \mathrm{mol})$ (online supplementary table 2 ). Furthermore, there were significantly
A

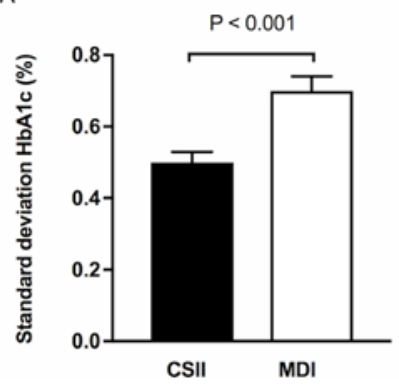

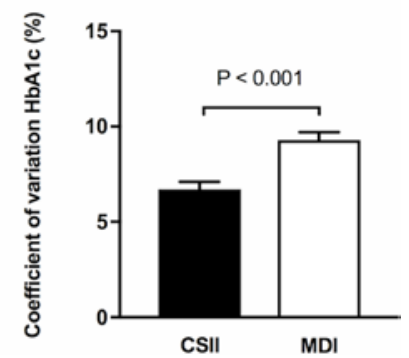

Figure 1 Long-term glycaemic (HbA1c) variability in 164 CSII and $342 \mathrm{MDI}$ participants. SD of HbA1c over followup $(0.5 \% \pm 0.4 \%(6 \pm 6) \mathrm{mmol} / \mathrm{mol} \mathrm{CSII}, 0.7 \% \pm 0.7 \%(9 \pm 8)$ $\mathrm{mmol} / \mathrm{mol} \mathrm{MDI}$ (A) and coefficient of variation of $\mathrm{HbA} 1 \mathrm{c}$ over follow-up $(6.7 \% \pm 4.6 \%(10 \pm 10) \mathrm{mmol} / \mathrm{mol}$ CSII, $9.3 \% \pm 7.3 \%(14 \pm 13) \mathrm{mmol} / \mathrm{mol} \mathrm{MDI})(\mathrm{B})$. Black bars=CSII; white bars $=$ MDI. Graphed values are mean \pm SEM $p<0.001$. CSII,continuous subcutaneous insulin infusion; HbA1c, glycated haemoglobin;MDI, multiple dailyinjection. 

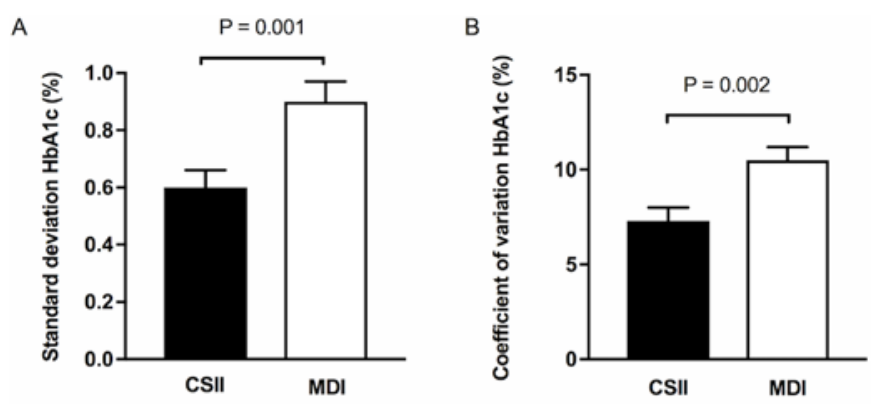

C
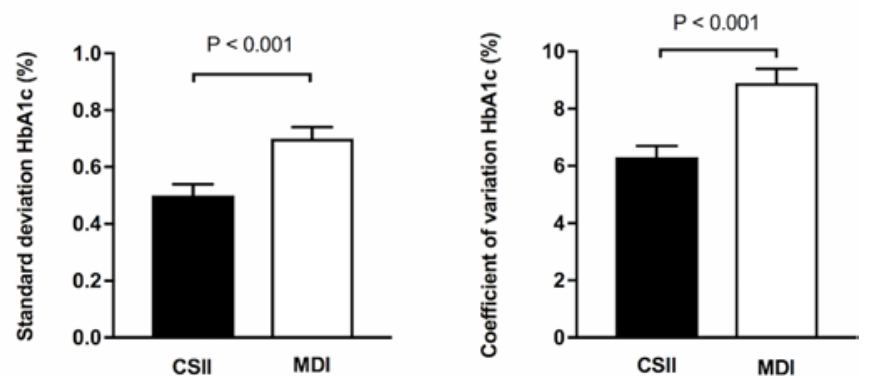

Figure 2 Long-term glycaemic variability by predefined age groups. Adults aged 18 to 26 years $(n=54$ on CSII, $\mathrm{n}=69$ on $\mathrm{MDI}) \mathrm{SD}$ of $\mathrm{HbA} 1 \mathrm{c}(0.6 \% \pm 0.4 \%(7 \pm 8) \mathrm{mmol} / \mathrm{mol}$ CSII, $0.9 \% \pm 0.6 \%(11 \pm 7) \mathrm{mmol} / \mathrm{mol} \mathrm{MDI} ; \mathrm{p}=0.001)(\mathrm{A})$, coefficient of variation $\mathrm{HbA} 1 \mathrm{c}$ over follow-up $(7.3 \% \pm 5.5 \%$ $(12 \pm 16) \mathrm{mmol} / \mathrm{mol}$ CSII, $10.5 \% \pm 5.9 \%(16 \pm 12) \mathrm{mmol} / \mathrm{mol}$ MDI; $p=0.002)(B)$, adults aged $\geq 26$ years (110 CSII, 273 MDI) SD of $\mathrm{HbA} 1 \mathrm{c}(0.5 \% \pm 0.4 \%(5 \pm 4) \mathrm{mmol} / \mathrm{mol} \mathrm{CSII}$, $0.7 \% \pm 0.7 \%(9 \pm 8) \mathrm{mmol} / \mathrm{mol} \mathrm{MDI} ; \mathrm{p}<0.001)(\mathrm{C})$, coefficient of variation over follow-up $(6.3 \% \pm 4.2 \%(9 \pm 5) \mathrm{mmol} / \mathrm{mol} \mathrm{CSI}$, $8.9 \% \pm 7.6 \%(14 \pm 13) \mathrm{mmol} / \mathrm{mol} \mathrm{MDI} ; \mathrm{p}<0.001)$ (D). Black bars $=$ CSII; white bars $=$ MDI. Graphed values are mean \pm SEM. CSII,continuous subcutaneous insulin infusion; HbA1c, glycated haemoglobin;MDI, multiple dailyinjection.

lower HbA1c SD and CV over follow-up among both age groups treated with CSII versus those treated with MDI (figure 2).

\section{HbA1c variability lower in CSII users across all tertiles of mean HbA1c mean}

HbA1c GV was assessed by tertile of mean HbA1c (tertile $1 \mathrm{HbA} 1 \mathrm{c} \leq 7.2 \%$ (55 mmol $/ \mathrm{mol})$, tertile $2 \mathrm{HbA} 1 \mathrm{c} \leq 8.3 \%$ $(67 \mathrm{mmol} / \mathrm{mol})$, tertile $3 \mathrm{HbA} 1 \mathrm{c} \leq 15.0 \%$ (140 mmol/ mol) (table 2). HbA1c CV was significantly lower in CSII versus MDI users at any tertile of mean HbA1c, whereas HbA1c SD was lower in CSII users only in tertiles 2 and 3. There was no interaction between HbA1c SD and CV and insulin modality at any tertile of mean HbA1c $(p=0.28$ and $\mathrm{p}=0.65$ for SD and CV, respectively).

\section{Lower HbA1c GV in adults changing from MDI to CSII}

Fifty-six adults chose to change their insulin delivery modality from MDI to CSII. These individuals had a mean \pm SD age of $36 \pm 14$ years $(35 \pm 12$ for women and $40 \pm 17$ for men), diabetes duration of $16 \pm 13$ years and $73 \%$
Table $2 \mathrm{HbA1c}$ GV by tertile of mean $\mathrm{HbA} 1 \mathrm{c}$

\begin{tabular}{lllll}
\hline & Tertile & CSII & MDI & P value \\
\hline $\mathrm{HbA1c}$ SD & 1 & $0.4 \pm 0.2$ & $0.5 \pm 0.4$ & 0.99 \\
& 2 & $0.5 \pm 0.4$ & $0.6 \pm 0.5$ & 0.99 \\
& 3 & $0.8 \pm 0.5$ & $1.1 \pm 0.9$ & $\mathbf{0 . 0 0 8}$ \\
$\mathrm{HbA1c}$ CV & 1 & $5.3 \pm 3.1$ & $7.5 \pm 5.5$ & $\mathbf{0 . 0 0 1}$ \\
& 2 & $6.5 \pm 4.8$ & $8.3 \pm 6.5$ & $\mathbf{0 . 0 4}$ \\
& 3 & $8.6 \pm 5.4$ & $11.7 \pm 8.7$ & $\mathbf{0 . 0 0 7}$ \\
\hline
\end{tabular}

Data are mean \pm SD.

CSII, continuous subcutaneous insulin infusion; GV, glycaemic variability; HbA1c, glycated haemoglobin; MDI, multiple daily injection.

were female. The observation period included 4.3 \pm 3.5 years on MDI and $4.6 \pm 4.7$ years on CSII after excluding the initial 12 months on CSII $(\mathrm{p}=0.56)$, during which the mean HbAlc fell significantly. There was a similar, significantly greater number of HbAlc measurements used to determine GV while on CSII compared with MDI; mean $\pm S D \quad(n=10 \pm 8$ and $n=9 \pm 7$, respectively; $p=0.002)$, and a shorter duration between HbAlc measurements while on CSII compared with MDI $(215 \pm 158$ and $336 \pm 501$ days, respectively; $\mathrm{p}<0.001$ ). HbAlc levels significantly decreased following the switch to CSII, including after excluding the first 12 months of HbAlc following modality change, mean \pm SD $(7.8 \% \pm 0.8 \%(62 \pm 9) \mathrm{mmol} /$ mol MDI vs $7.4 \% \pm 0.9 \% \quad(57 \pm 10) \quad \mathrm{mmol} / \mathrm{mol} \mathrm{CSII}$; $\mathrm{p}<0.001$ ) (figure 3A). In addition, CSII use lowered HbAlc variability, with CSII commencement decreasing both HbAlc SD $(0.7 \% \pm 0.5 \%(8 \pm 5) \mathrm{mmol} / \mathrm{mol}$ MDI vs $0.4 \% \pm 0.4 \%(5 \pm 4) \mathrm{mmol} / \mathrm{mol} \mathrm{CSII} ; \mathrm{p}<0.001)$ and HbAlc CV $(9.2 \% \pm 5.5 \%(13 \pm 8) \mathrm{mmol} / \mathrm{mol}$ MDI vs $6.1 \% \pm 3.9 \%$ $(9 \pm 5) \mathrm{mmol} / \mathrm{mol} \mathrm{CSII} ; \mathrm{p}=0.004$ ) (figure 3B,C). There were no statistically significant correlations between the improvement in HbA1c SD or CV with baseline variables such as age and diabetes duration (data not shown). The change in HbA1c, HbA1c SD and CV was analysed by gender and there were similar improvements in both men and women (online supplementary table 3 ).

The 56 adults who changed from MDI to CSII were matched (by age, baseline HbAlc and duration of follow-up) to 56 adults who remained on MDI (table 3 ). There were no statistically significant differences in baseline HbAlc, age, years of follow-up nor time between HbAlc measurements. Individuals who changed to CSII had more HbA1c values following the modality change, compared with those who remained on MDI (post-CSII $\mathrm{n}=10 \pm 8$ vs time 2 remained on MDI $\mathrm{n}=8 \pm 6 ; \mathrm{p}=0.048$ ). In contrast to the adults who changed from MDI to CSII, the adults who remained on MDI did not significantly improve mean, SD or coefficient of variation HbA1c.

\section{DISCUSSION}

In this retrospective audit of 506 adults with T1DM from two independent Australian tertiary referral diabetes 
A

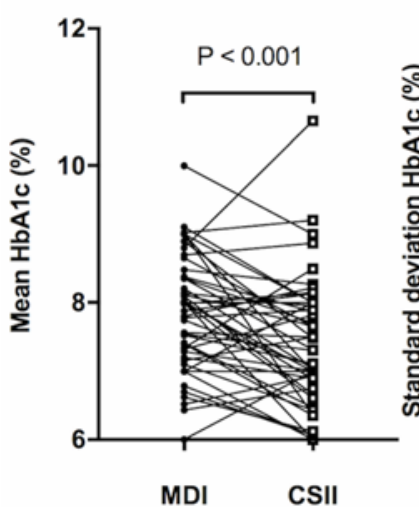

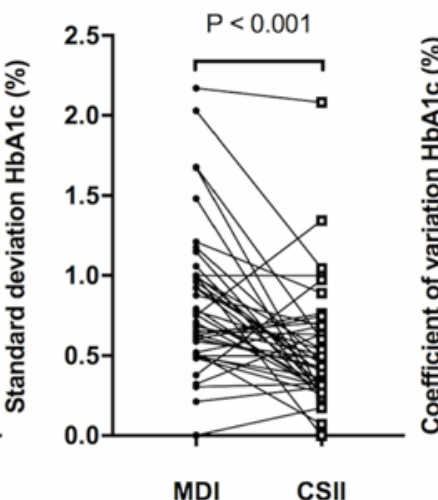

C

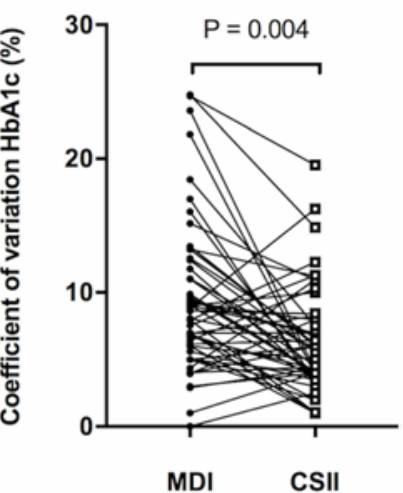

Figure 3 Long-term glycaemic variability in individuals changing from MDI to CSII therapy. Fifty-six adults changed from MDI to CSII therapy over the study. Mean HbA1c over follow-up $(p<0.001)(A), S D$ of HbA1c $(p<0.001)(B)$ and coefficient of variation of HbA1c over follow-up $(p=0.004)$ (C). Black circles=MDI; white squares=CSII. Graphed values are mean pre-therapy and posttherapy change. CSII,continuous subcutaneous insulin infusion; HbA1c, glycated haemoglobin;MDI, multiple dailyinjection.

centres, we report the novel finding that CSII therapy was associated with lower long-term (HbA1c) glycaemic variability than MDI therapy, despite similar mean HbA1c levels across the two modalities. Participants treated by CSII (without regular RT-CGM, low glucose suspend, predictive low glucose suspend or closed loop functions and without regular flash glucose monitoring) had significantly lower HbAlc variability reflected by both SD and CV measures. GV among CSII users remained significantly lower after adjustment for age, gender, diabetes duration, hospital location, socioeconomic status, chronic complication status, severe hypoglycaemia, baseline HbA1c levels, years of follow-up, number of HbA1c measures and time between HbAlc measures. The groups of emerging and more mature adults showed similar HbAlc GV responses, as did males and females. The impact of CSII on HbA1c CV was consistent across all tertiles of mean HbA1c. Similar statistically significant reductions in both measures of HbA1c GV were seen with 56 patients who changed from MDI to CSII therapy, while MDI users who remained on MDI for a similar follow-up time did not significantly change their HbA1c GV.

Glycaemic variability has been identified as an independent risk factor for the chronic complications of diabetes, ${ }^{67}$ and in a large Swedish diabetes registry based epidemiologic study CSII use was independently associated with a significantly lower risk of cardiovascular complications and death. ${ }^{5}$ This finding may at least partly relate to GV, and fluctuations between hyperglycaemia and hypoglycaemia inducing inflammation and oxidative

Table 3 Glycaemic variability in individuals changing from MDI to CSII compared with matched individuals remaining on MDI

\begin{tabular}{|c|c|c|c|c|c|c|}
\hline & \multicolumn{3}{|l|}{ MDI to CSII } & \multicolumn{3}{|c|}{ Remained on MDI } \\
\hline & Pre-CSII & Post-CSII & P value* & Time 1 & Time 2 & $\mathrm{P}$ value \\
\hline $\mathrm{N}$ & 56 & & & 56 & & \\
\hline Age (years) & $36 \pm 13.5$ & & & $38 \pm 15.7$ & & \\
\hline $\begin{array}{l}\text { Baseline } \mathrm{HbA1c} \\
\%(\mathrm{mmol} / \mathrm{mol})\end{array}$ & $\begin{array}{l}7.9 \pm 1.4 \\
(63 \pm 15.7)\end{array}$ & & & $\begin{array}{l}7.9 \pm 1.5 \\
(63 \pm 16.3)\end{array}$ & & \\
\hline Study follow-up (years) & $10.0 \pm 5.9$ & & & $9.4 \pm 6.5$ & & \\
\hline HbA1c measurements ( $n$ ) & $9 \pm 7$ & $10 \pm 8$ & 0.002 & $8 \pm 8$ & $8 \pm 6$ & 1.00 \\
\hline Time between HbA1c (days) & $336 \pm 501$ & $215 \pm 158$ & $<0.001$ & $281 \pm 206$ & $238 \pm 166$ & 0.18 \\
\hline $\begin{array}{l}\text { Mean HbA1c } \\
\%(\mathrm{mmol} / \mathrm{mol})\end{array}$ & $7.8 \pm 0.8(62 \pm 9))$ & $7.4 \pm 0.9(57 \pm 10)$ & $<0.001$ & $\begin{array}{l}7.7 \pm 1.1 \\
(61 \pm 12)\end{array}$ & $\begin{array}{l}7.7 \pm 1.2 \\
(61 \pm 13)\end{array}$ & 0.64 \\
\hline $\begin{array}{l}\mathrm{HbA} 1 \mathrm{c} \mathrm{SD} \\
\%(\mathrm{mmol} / \mathrm{mol})\end{array}$ & $\begin{array}{l}0.7 \pm 0.5 \\
(8 \pm 5)\end{array}$ & $\begin{array}{l}0.4 \pm 0.4 \\
(5 \pm 4)\end{array}$ & $<0.001$ & $\begin{array}{l}0.6 \pm 0.5 \\
(7 \pm 5)\end{array}$ & $\begin{array}{l}0.5 \pm 0.3) \\
(5 \pm 3)\end{array}$ & 0.10 \\
\hline $\begin{array}{l}\mathrm{HbA1c} \mathrm{CV} \\
\%(\mathrm{mmol} / \mathrm{mol})\end{array}$ & $9.2 \pm 5.6(13 \pm 8)$ & $6.1 \pm 3.9(9 \pm 5)$ & 0.004 & $\begin{array}{l}7.8 \pm 5.2 \\
(11 \pm 7)\end{array}$ & $\begin{array}{l}6.4 \pm 3.5 \\
(9 \pm 5)\end{array}$ & 0.12 \\
\hline
\end{tabular}

Data are mean \pm SD.

${ }^{*}$ Pre-CSII (on MDI) versus post-CSII

†Remains on MDI time 1 versus time 2.

CSII, continuous subcutaneous insulin infusion; CV, coefficient of variation; HbA1c, glycated haemoglobin; MDI, multiple daily injection. 
stress and epigenetic changes. ${ }^{24}$ We speculate that lower HbAlc variability, as associated with CSII use in our study, may underpin or at least contribute to the observed reduced chronic complication and death rates among CSII users. ${ }^{5} 6819 \mathrm{HbAlc}$ variability has been implicated in the development of microvascular complications in $\mathrm{T} 1 \mathrm{DM},{ }^{20}$ although the associations with retinopathy have not been as consistent reported as for nephropathy. ${ }^{621-25}$ Only one study has found an independent association of HbA1c GV with cardiovascular events in T1DM. ${ }^{26}$ There have been no studies which have reported an association with increased HbA1c GV and mortality risk, although a number of groups have found such an association in type 2 diabetes mellitus. ${ }^{27-29}$

There may be divergent effects of insulin treatment modality on measures of short-term (blood or interstitial fluid glucose level based) and long-term (HbA1c) glucose variability. We have previously demonstrated in 119 adult individuals with T1DM (77 MDI and 42 CSII users) no statistically significant difference in any of 12 accepted measures of short-term glucose variability over 48 hours when analysed by masked CGM. ${ }^{30}$ Unfortunately, due to the costly nature of CGM in Australia at the time of the study, when it was predominantly selffunded, only a very small subset of patients used episodic RT-CGM and usually less than the $70 \%$ of time described as needed to improve glycaemia. ${ }^{31}$ These negative results are comparable to other studies assessing short-term (CGM) glucose variability in CSII users, ${ }^{8} 1232$ all of which assessed GV over a maximum of 3 days. Recent consensus guidelines have recommended that CGM should occur for 14 days to accurately assess glucose profile, ${ }^{31}$ and therefore the inconsistencies in GV benefit may reflect inadequate CGM data. Furthermore, improvements in short-term GV with CSII may be impacted by deterioration in HbAlc overtime, ${ }^{32}$ highlighting the importance of assessing long-term GV. Even in studies in which HbAlc levels were significantly improved by CSII or CSII with RT-CGM, short-term GV did not improve in all participants. ${ }^{1433}$ More recent studies, including those achieving tight glycaemic control, ${ }^{34}$ or using RT-CGM and insulin pumps with low-glucose suspend functions, ${ }^{35}$ overnight closed loop insulin delivery ${ }^{36}$ or hybrid closed loop CSII, ${ }^{37}$ have demonstrated improved short-term glucose variability. The benefit of RT-CGM on short-term GV in the absence of CSII therapy has been demonstrated in the DIAMOND and GOLD trials ${ }^{38} 39$ which may be a more cost-effective therapeutic option. However, none of these studies have reported HbA1c GV change. We anticipate that technological advances in pumps, sensors and control algorithms will continue to reduce short-term GV, and also long-term GV, in both adults and children with T1DM. It is important to consider whether study participants are in clinical trials, with their inherent selection biasses and often additional participant support, or in clinical practice (as herein).

\section{Strengths and limitations}

This is a real-world study, rather than a clinical trial with potential for selection bias and the Hawthorne (observer) effect. ${ }^{40}$ We assessed relatively large numbers of adults with T1DM from two independent tertiary hospitals and did so over a relatively long follow-up period with good numbers of HbA1c measures from accredited pathology services in both CSII and MDI users, and fortunately with similar mean HbA1c in both groups. We report both HbA1c CV and SD and not unexpectedly (given the mathematical derivation of SD from CV), find similar results with both measures. The study is strengthened by the analysis of GV over a wide adult age range, as well as by pre-established age groups and by consideration of gender. We assessed the impact of GV among tertiles of mean HbAlc, and in contrast to previous studies, ${ }^{10}$ found that the impact of insulin modality on $\mathrm{HbA1c} \mathrm{CV}$ persisted across varying levels of glycaemic control. As well as a longitudinal observational study there was also an observation of a group changing from MDI to CSII therapy, and comparison to a matched group who remained on MDI. There was a similar number of HbAlc measurements included in the MDI and CSII groups over a long period of follow-up (4years in established users, and 10 years in those who changed from MDI to CSII). HbAlc GV is a low cost measure that could be calculated from routine clinical care data (of HbA1c levels), hence is readily applicable to clinical practice (particularly in the era of electronic medical records), and clinical trials. Study limitations are that this clinical audit does not include many patients attending private practices, except for a small subset of the SVH patients who attended a bulk-billing (no cost to patients) private practice on the public hospital grounds, though in Australia CSII therapy is more commonly provided in public hospitals than in private practice and in order to obtain their insulin pump most CSII users have private health insurance. ${ }^{41}$ We acknowledge that there may be treatment differences between the two hospital sites and the bias toward CSII use in the SVH site (due to their interest in and early provision of CSII services in Australia) may impact results. We addressed this by analysing CSII and MDI users by hospital location and found similarly lower GV in the CSII groups. HbA1c measures were performed in different laboratories and likely by different methodologies, though all laboratories were NATA accredited and participants usually attended the same pathology provider. Given the observational nature of the study, we are unable to account for all differences between the MDI and CSII groups, including treatment adherence, motivation and health literacy. We note that the time interval between HbAlc measures is shorter for CSII than MDI (mean difference of 36 days) and this may reflect behavioural differences or more healthcare involvement. However, time interval and number of $\mathrm{HbA1c}$ measures were statistically adjusted for in the data analyses. We did not record patient diabetes education provided to both groups, however all individuals attended clinics with access to diabetes educators, 
dieticians and clinicians, that were free of charge to them and usually at the same clinic visit. We acknowledge that more time may have been spent with CSII users for initial CSII education, ${ }^{18}$ however the initial 12 months of HbAlc data following CSII commencement, when greater education time was likely provided, was excluded from the study. Therefore, the observed prolonged benefit on glycaemic variability is less likely to be due to initial education. Other groups have examined the impact of CSII therapy compared with MDI on glycaemic control when equal education time is provided. ${ }^{1642}$ The results have not been consistent, and a recent RCT failed to show clinical and economic benefit of CSII. ${ }^{42}$ Neither study measured long-term GV. We acknowledge that figures related to severe hypoglycaemia event rates, retrieved from medical records, may not be accurate.

Future research directions include confirmatory studies in both adult and paediatric groups with T1DM, linkage of both short-term and long-term measures of glucose variability to hard clinical events and the effects of pumps with RT-CGM, closed loop insulin delivery systems, bihormonal pumps and insulin adjunct therapies (such as sodium glucose cotransporter 2 (SGLT2) inhibitors, metformin and incretin-modulating drugs) on glycaemic variability. Mechanistic studies exploring the clinical, cellular and molecular effects of glycaemic variability are also of relevance. It is imperative that further research addresses the cost benefits of CSII therapy and of RT-CGM therapy to facilitate equitable technology access. Analyses of long-term outcome data to determine recommended $\mathrm{HbA1c}$ GV targets are also desirable.

In summary, this study has shown that CSII use is associated with lower HbAlc glycaemic variability in adults with T1DM. HbA1c variability, a simple and low cost measure, thought to modulate chronic diabetes complication risk, should be a routine tool to assess glycaemic control in clinical practice and in clinical research and trials.

\section{Author affiliations}

${ }^{1}$ NHMRC Clinical Trials Centre, University of Sydney, Camperdown, New South Wales, Australia

${ }^{2}$ Department of Diabetes, Endocrinology and Metabolism, Royal North Shore Hospital, St Leonards, New South Wales, Australia

${ }^{3}$ Northern Clinical School, Faculty of Medicine, University of Sydney, St Leonards, New South Wales, Australia

${ }^{4}$ The University of Melbourne Medicine at St Vincent's Hospital, Fitzroy, Victoria, Australia

${ }^{5}$ Department of Medicine, University of Melbourne, Melbourne, Victoria, Australia

${ }^{6}$ Department of Endocrinology and Diabetes, St Vincent's Hospital Melbourne, Melbourne, Victoria, Australia

Acknowledgements Authors thank all patients, clinicians, scientists and administration team members in the participating clinics.

Contributors ES researched the RNS data, analysed the data and wrote the manuscript. RM contributed to RNS data collection and reviewed the manuscript. ASJ facilitated SVH data collection and reviewed the manuscript. DC contributed to SVH data collection. AH reviewed the manuscript. DNO contributed to data generation and collection at SVH and reviewed the manuscript. GF contributed to data generation and collection at RNSH and reviewed the manuscript. AJJ contributed to study design, data generation and collection at SVH and contributed to writing of the manuscript. All authors contributed to data interpretation. AJJ is the guarantor.
Funding The authors have not declared a specific grant for this research from any funding agency in the public, commercial or not-for-profit sectors.

Competing interests Funding (scholarships for ES) were provided by NHMRC (Australia), JDRF Australia, the University of Sydney and the Royal Australasian College of Physicians Vincent Fairfax Award. AJJ was supported by a NHMRC Practitioner Fellowship and funding from the NHMRC Clinical Trials Centre and is a Sydney Medical Foundation School Fellow. AAH is supported by a career development award from the JDRF Australia T1D Clinical Research Network.

Patient consent for publication Not required.

Ethics approval The study was approved by the Human Research Ethics Committees of the Northern Sydney Local Health District and St Vincent's Hospital Melbourne.

Provenance and peer review Not commissioned; externally peer reviewed.

Data availability statement No data are available. All data relevant to the study are included in the article or uploaded as supplementary information. The study was a retrospective audit of two tertiary hospital medical records. We do not have ethics approval to share this data.

Open access This is an open access article distributed in accordance with the Creative Commons Attribution Non Commercial (CC BY-NC 4.0) license, which permits others to distribute, remix, adapt, build upon this work non-commercially, and license their derivative works on different terms, provided the original work is properly cited, appropriate credit is given, any changes made indicated, and the use is non-commercial. See: http://creativecommons.org/licenses/by-nc/4.0/.

\section{ORCID iDs}

Emma S Scott http://orcid.org/0000-0002-6795-8198

David N O'Neal http://orcid.org/0000-0002-0870-4032

\section{REFERENCES}

1 The effect of intensive treatment of diabetes on the development and progression of long-term complications in insulin-dependent diabetes mellitus. The diabetes control and complications trial Research Group. N Engl J Med 1993;329:977-86.

2 Piconi L, Quagliaro L, Assaloni R, et al. Constant and intermittent high glucose enhances endothelial cell apoptosis through mitochondrial superoxide overproduction. Diabetes Metab Res Rev 2006;22:198-203.

3 Polhill TS, Saad S, Poronnik P, et al. Short-Term peaks in glucose promote renal fibrogenesis independently of total glucose exposure. Am J Physiol Renal Physiol 2004;287:F268-73.

4 Ceriello A, Esposito K, Piconi L, et al. Oscillating glucose is more deleterious to endothelial function and oxidative stress than mean glucose in normal and type 2 diabetic patients. Diabetes 2008;57:1349-54.

5 Steineck I, Cederholm J, Eliasson B, et al. Insulin pump therapy, multiple daily injections, and cardiovascular mortality in 18 168 people with type 1 diabetes: observational study. BMJ 2015;350:h3234.

6 Kilpatrick ES, Rigby AS, Atkin SL. A1C variability and the risk of microvascular complications in type 1 diabetes: data from the diabetes control and complications trial. Diabetes Care 2008;31:2198-202.

7 Virk SA, Donaghue KC, Cho YH, et al. Association between HbA1c variability and risk of microvascular complications in adolescents with type 1 diabetes. J Clin Endocrinol Metab 2016;101:3257-63.

8 Zabeen B, Craig ME, Virk SA, et al. Insulin pump therapy is associated with lower rates of retinopathy and peripheral nerve abnormality. PLoS One 2016;11:e0153033.

9 Misso ML, Egberts KJ, Page M, et al. Continuous subcutaneous insulin infusion (CSII) versus multiple insulin injections for type 1 diabetes mellitus. Cochrane Database Syst Rev 2010;1.

10 Lepore G, Corsi A, Dodesini AR, et al. Continuous subcutaneous insulin infusion is better than multiple daily insulin injections in reducing glucose variability only in type 1 diabetes with good metabolic control. Diabetes Care 2010;33:e81.

11 Simon B, Treat V, Marco C, et al. A comparison of glycaemic variability in CSII vs. MDI treated type 1 diabetic patients using CGMS. Int J Clin Pract 2008;62:1858-63.

12 Alemzadeh R, Palma-Sisto P, Parton EA, et al. Continuous subcutaneous insulin infusion and multiple dose of insulin regimen display similar patterns of blood glucose excursions in pediatric type 1 diabetes. Diabetes Technol Ther 2005;7:587-96. 
13 Fendler W, Baranowska Al, Mianowska B, et al. Three-Year comparison of subcutaneous insulin pump treatment with multi-daily injections on $\mathrm{HbA1c}$, its variability and hospital burden of children with type 1 diabetes. Acta Diabetol 2012;49:363-70.

14 Jenkins AJ, Krishnamurthy B, Best JD, et al. Evaluation of an algorithm to guide patients with type 1 diabetes treated with continuous subcutaneous insulin infusion on how to respond to real-time continuous glucose levels: a randomized controlled trial. Diabetes Care 2010;33:1242-8.

15 Census of Population and Housing: socio-economic indexes for areas (SEIFA) Australia [Internet], 2011. Available: http://www.abs. gov.au/AUSSTATS/abs@.nsf/DetailsPage/2039.02006 [Accessed 1 Nov 2017].

16 Cohen ND, Hong ES, Van Drie C, et al. Long-Term metabolic effects of continuous subcutaneous insulin infusion therapy in type 1 diabetes. Diabetes Technol Ther 2013;15:544-9.

17 Calandro DA, Januszewski AS, Cuper KK, et al. Substantial and sustained $\mathrm{HbA} 1 \mathrm{c}$ reductions in Australian insulin pump services for adults with type 1 diabetes. benefit also evident for older and high HbA1c subjects. Madridge J Diabetes 2016;1:23-8.

18 Xu S, Alexander K, Bryant W, et al. Healthcare professional requirements for the care of adult diabetes patients managed with insulin pumps in Australia. Intern Med J 2015;45:86-93.

19 Rosenlund S, Hansen TW, Andersen S, et al. Effect of 4 years subcutaneous insulin infusion treatment on albuminuria, kidney function and $\mathrm{HbA}$ compared with multiple daily injections: a longitudinal follow-up study. Diabetic Medicine 2015;32:1445-52.

20 Gorst C, Kwok CS, Aslam S, et al. Long-Term glycemic variability and risk of adverse outcomes: a systematic review and metaanalysis. Diabetes Care 2015;38:2354-69.

21 Nazim J, Fendler W, Starzyk J. Metabolic control and its variability are major risk factors for microalbuminuria in children with type 1 diabetes. Endokrynol Pol 2014;65:83-9.

22 Hermann JM, Hammes H-P, Rami-Merhar B, et al. Hba1C variability as an independent risk factor for diabetic retinopathy in type 1 diabetes: a German/Austrian multicenter analysis on 35,891 patients. PLoS One 2014;9:e91137.

23 Marcovecchio ML, Dalton RN, Chiarelli F, et al. A1C variability as an independent risk factor for microalbuminuria in young people with type 1 diabetes. Diabetes Care 2011;34:1011-3.

24 Raman S, Dai H, DeLurgio SA, et al. High hemoglobin A1c variability is associated with early risk of microalbuminuria in children with T1D. Pediatr Diabetes 2016;17:398-406.

25 Hietala K, Wadén J, Forsblom C, et al. Hba1C variability is associated with an increased risk of retinopathy requiring laser treatment in type 1 diabetes. Diabetologia 2013;56:737-45.

26 Waden J, Forsblom C, Thorn LM, et al. A1C variability predicts incident cardiovascular events, microalbuminuria, and overt diabetic nephropathy in patients with type 1 diabetes. Diabetes 2009;58:2649-55.

27 Forbes A, Murrells T, Mulnier $\mathrm{H}$, et al. Mean $\mathrm{HbA}_{1 \mathrm{c}}, \mathrm{HbA}_{1 \mathrm{c}}$ variability, and mortality in people with diabetes aged 70 years and older: a retrospective cohort study. Lancet Diabetes Endocrinol 2018;6:476-86.

28 Critchley JA, Carey IM, Harris T, et al. Variability in glycated hemoglobin and risk of poor outcomes among people with type
2 diabetes in a large primary care cohort study. Diabetes Care 2019;42:2237-46.

29 Cardoso CRL, Leite NC, Moram CBM, et al. Long-Term visit-tovisit glycemic variability as predictor of micro- and macrovascular complications in patients with type 2 diabetes: the Rio de Janeiro type 2 diabetes cohort study. Cardiovasc Diabetol 2018;17:33.

30 Scott ES, McGrath RT, Januszewski AS, et al. Short-Term glucose variability in adults with type 1 diabetes does not differ between insulin pump and multiple daily injection users - a masked continuous glucose monitoring study in clinical practice. Diabetes Metab 2018.

31 Danne T, Nimri R, Battelino T, et al. International consensus on use of continuous glucose monitoring. Diabetes Care 2017;40:1631-40.

32 Harrington J, Peña AS, Wilson L, et al. Vascular function and glucose variability improve transiently following initiation of continuous subcutaneous insulin infusion in children with type 1 diabetes. Pediatr Diabetes 2013;14:504-11.

33 Buse JB, Kudva YC, Battelino T, et al. Effects of sensor-augmented pump therapy on glycemic variability in well-controlled type 1 diabetes in the StAR 3 study. Diabetes Technol Ther 2012;14:644-7.

34 Šoupal J, Petruželková L, Flekač M, et al. Comparison of different treatment modalities for type 1 diabetes, including sensoraugmented insulin regimens, in 52 weeks of follow-up: a COMISAIR study. Diabetes Technol Ther 2016;18:532-8.

35 Rosenlund S, Hansen TW, Rossing P, et al. Effect of sensoraugmented pump treatment versus multiple daily injections on albuminuria: a 1-year randomized study. J Clin Endocrinol Metab 2015;100:4181-8.

36 Renard E, Farret A, Kropff J, et al. Day-and-Night closed-loop glucose control in patients with type 1 diabetes under free-living conditions: results of a single-arm 1-Month experience compared with a previously reported feasibility study of evening and night at home. Diabetes Care 2016;39:1151-60.

37 Garg SK, Weinzimer SA, Tamborlane WV, et al. Glucose outcomes with the in-home use of a hybrid closed-loop insulin delivery system in adolescents and adults with type 1 diabetes. Diabetes Technol Ther 2017;19:155-63.

38 Beck RW, Riddlesworth T, Ruedy K, et al. Effect of continuous glucose monitoring on glycemic control in adults with type 1 diabetes using insulin injections. JAMA 2017;317:371-8.

39 Lind M, Polonsky W, Hirsch IB, et al. Continuous glucose monitoring vs conventional therapy for glycemic control in adults with type 1 diabetes treated with multiple daily insulin injections. JAMA 2017;317:379-87.

40 McCambridge J, Witton J, Elbourne DR. Systematic review of the Hawthorne effect: new concepts are needed to study research participation effects. J Clin Epidemiol 2014;67:267-77.

41 Insulin pump use in Australia [Internet], 2012. Available: http://aihw. gov.au [Accessed 16 Feb 2017].

42 Heller S, White D, Lee E, et al. A cluster randomised trial, costeffectiveness analysis and psychosocial evaluation of insulin pump therapy compared with multiple injections during flexible intensive insulin therapy for type 1 diabetes: the repose trial. Health Technol Assess 2017;21:1-278. 